\title{
A RAPID AND INEXPENSIVE METHOD FOR THE PURIFICATION OF DNA FROM LICHENS AND THEIR SYMBIONTS
}

\author{
Daniele ARMALEO^ and Philippe CLERC $¥$
}

\begin{abstract}
A simple DNA extraction method is described, applicable to many different kinds of lichens. The method involves the use of the detergents DTAB and CTAB and yields DNA that can be directly amplified with the polymerase chain reaction or digested with restriction enzymes.
\end{abstract}

\section{Introduction}

The extraction of DNA from eukaryotic organisms yields mixtures of organellar and nuclear DNA unless special precautions are taken to separate subcellular fractions. In the case of lichens, which are constituted by two or more eukaryotic or prokaryotic symbionts, DNA extraction yields even more complex mixtures. Possible experimental problems arising from this genomic heterogeneity can be avoided by separating the symbionts prior to DNA extraction through culturing (Ahmadjian et al. 1987; Kardish et al. 1990; Friedl, unpublished data) or thallus dissection (Clerc, unpublished data; DePriest \& Been 1992). For some molecular studies, specific DNA subfractions can be amplified from complex genomic mixtures using selective primers (Gargas \& Taylor 1992) in the PCR.

The purification of lichen DNA presents additional problems due to the persistence of contaminants in the preparations. Earlier reported uses of lichen DNA, such as solution hybridization (Blum \& Kashevarov 1986) or gel electrophoresis (Ahmadjian et al. 1987) did not require high-purity preparations. However, a high degree of purity is needed for restriction enzyme digestions or PCR, which are frequent initial steps in the detailed analysis of DNA. These reactions are often inhibited with lichen DNA extracted by procedures applied to fungi and reviewed by Taylor \& Natvig (1987), unless special steps are taken to remove the inhibitory contaminants (Kardish et al. 1990; Armaleo \& Clerc 1991). Secondary products in lichen thalli are not the problem, as the intractability of lichen DNA remains whether or not secondary products are removed prior to DNA extraction (in addition, most DNA preparations involve phenol and/or chloroform, which are likely to remove secondary products). Polysaccharides, ubiquitous and abundant components of lichen thalli (review by Common 1991), are the problem, as they often

Abbreviations: $\mathrm{CTAB}=$ Hexadecyltrimethyl ammonium bromide; $\mathrm{DTAB}=$ Dodecyltrimethyl ammonium bromide; $P C R=$ polymerase chain reaction.

^Department of Botany, Duke University, Durham, NC 27708-0338, USA.

$\ddagger$ Conservatoire et Jardin Botaniques, Ch. de l'Impératrice 1, Case Postale $60 \mathrm{CH}-1292$ Chambésy/GE, Switzerland. 
co-purify with the relatively small amount of nucleic acids obtainable from lichens. The chemical properties that polysaccharides share with DNA (polymeric nature, water solubility, sugars, charges) underlie the frequent co-purification and the resulting inhibition of restriction enzymes or polymerases. Among the commonly used steps in DNA extractions, phenol/ chloroform may not remove enough polysaccharides, and ethanol precipitates them with the DNA.

For the above reasons, an earlier procedure developed for the isolation of lichen DNA and RNA included a final mini-column purification step to remove remaining contaminants and yielded DNA amenable to molecular manipulation (Armaleo \& Clerc 1991). The mini-column and other final cleaning methods, such as caesium chloride gradient centrifugation (Kardish et al. 1990) or gel purification, add time and cost and decrease yields. The method described in this paper, modified from a procedure for isolating DNA from whole human blood (Gustincich et al. 1991), was developed to simplify the purification of lichen DNA by reducing time and cost, and has been applied to many lichens belonging to a wide range of families (Lutzoni and Vilgalys 1994; Clerc and Amman, unpublished data; Spatafora et al., unpublished data). It was also used with isolated mycobionts (La Greca and Armaleo, unpublished data) and Trebouxia photobionts (Friedl, personal communication). The key feature is the removal of contaminants by selectively precipitating DNA with the detergent CTAB. Unlike the more common alcohol-induced precipitations, CTAB prevents or reduces the coprecipitation of polysaccharides (Jones 1963), and has been used in some procedures to isolate fungal DNA (Murray \& Thompson 1980; Zolan \& Pukkila 1986).

\section{Main features of the method}

1. The lichens' thick cell walls and polysaccharide matrix must be thoroughly ground to ensure complete release of the DNA.

2. The extraction buffer contains the detergent DTAB in a high ionic strength buffer $(1 \mathrm{M} \mathrm{NaCl})$, to provide the needed solubilization and denaturation power.

3. After a chloroform extraction that removes proteins, organic compounds, and some polysaccharides, the DNA is selectively precipitated from the aqueous phase at lower ionic strength $(\leq 400 \mathrm{mM} \mathrm{NaCl})$ in the presence of CTAB. Under these conditions, CTAB forms an insoluble salt with the DNA, while neutral polysaccharides remain soluble (Jones 1963).

4. Effective removal of contaminants requires a partial reiteration of the procedure followed by a final ethanol precipitation. The resulting DNA can be used directly for PCR or restrictions. As indicated below, in some cases the yield may be very low (Fig. 1, lane 1). PCR products obtained from preparations with no visible genomic DNA from the lichen should be considered with caution, as traces of DNA from other organisms may become amplified under those conditions. 


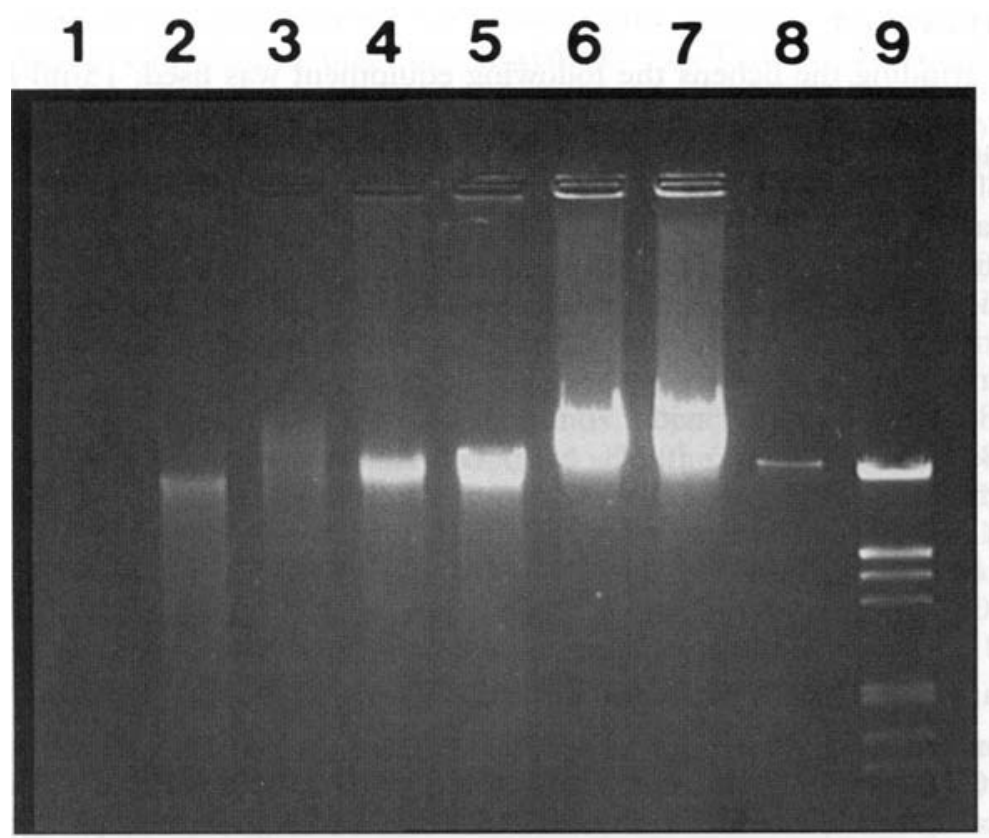

FIG. 1. Agarose-gel electrophoresis of DNA from representative lichens. Thalli were stored at $-80^{\circ} \mathrm{C}$ prior to DNA extraction. Electrophoresis was for $1 \mathrm{~h}$ at $20 \mathrm{~V} \mathrm{~cm}^{-1}$ in a $1 \%$ agarose gel with Tris-Borate-EDTA buffer in the presence of $0.5 \mu \mathrm{g} \mathrm{ml}^{-1}$ of ethidium bromide (Sambrook et al. 1989). The gel was photographed under UV illumination (Sambrook et al. 1989). Lanes 1-5 contain $10 \%$, and lanes $6-7$ contain $20 \%$ of the DNA obtained from the following taxa (the first of the two numbers in parentheses is the total nanograms of DNA extracted, the second is the milligrams of thallus used.): 1 , Ochrolechia frigida s.1. $(<5 ; 50) ; 2$, Verrucaria sp. $(100 ; 10) ; 3$, Lepraria lobificans $(100 ; 100) ; 4$, Lasallia papulosa $(300 ; 40) ; 5$, Graphis scripta (700; thallus weight undetermined, due to attached bark); 6, Cladina subtenuis $(1500 ; 128) ; 7$, Stereocaulon tomentosum (2000; 127). Lane 8: $5 \mathrm{ng}$ of lambda-phage DNA (Promega). Lane 9: molecular size markers (lambda-phage DNA digested with HindIII and EcoRI). The largest size marker is $21 \mathrm{~kb}$ long, and most of the visible lichen DNA is at or above the size. All the lichen DNAs, including the invisible amount obtained from Ochrolechia, yielded proper amplification products after PCR (not shown).

5. Processing one or two samples from thallus grinding to resuspension of the final pellet requires about $1.5 \mathrm{~h}$ and generally yields between $0 \cdot 1$ and $1 \mu \mathrm{g}$ of DNA for every $100 \mathrm{mg}$ of thallus (air-dry weight). Some lichens produce higher, some much lower yields (Fig. 1). If the lichen is fresh, is stored frozen, and is ground in liquid nitrogen (see below), the extracted DNA is largely undegraded, aside from mechanical shearing. Older and unfrozen specimens, herbarium samples, or lichens ground at room temperature, may yield DNA degraded to varying degrees.

6. The initial RNAase treatment eliminates RNA that may interfere with the PCR. By omitting RNAase RNA can be obtained, but its quality was not tested. 


\section{Materials used}

For grinding the lichens the following equipment was used: 15-ml Falcon tubes, glass beads (Thomas Scientific, 0.5 mm diameter, cat.\# 5663-R50), acetone (Mallinckrodt), a ceramic mortar and pestle (can be stored at $-80^{\circ} \mathrm{C}$ or cooled with liquid $\mathrm{N}_{2}$ ) and liquid $\mathrm{N}_{2}$. For small samples, white quartz sand (Sigma, $-50+70$ mesh) mortar-ground to a fine powder and autoclaved and microfuge tubes with a fitting pestle (Kontes pellet pestle) were employed. Chemicals used for extraction were: pancreatic RNAase A (Sigma), $10 \mathrm{mg}$ $\mathrm{ml}^{-1}$ in $\mathrm{H}_{2} \mathrm{O}$, heated to $100^{\circ} \mathrm{C}$ for $5 \mathrm{~min}$ to eliminate possible DNAase contamination, and stored at $-20^{\circ} \mathrm{C}$; DTAB buffer (Sigma) $[5.5 \%(\mathrm{w} / \mathrm{v}$ ) DTAB in $1 \mathrm{M} \mathrm{NaCl}$ with $70 \mathrm{~mm}$ Tris, $\mathrm{pH} 8.6$, and $30 \mathrm{~mm}$ EDTA]; CTAB solution (Sigma) $[0.5 \%$ (w/v) CTAB in $40 \mathrm{~mm} \mathrm{NaCl}$; chloroform (Mallinckrodt); $1.2 \mathrm{M} \mathrm{NaCl}$; absolute ethanol; $70 \%$ ethanol; and TE buffer

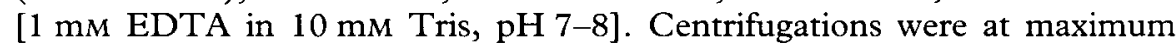
speed $(13000-15000 \mathrm{rpm}$, from 12000 to $14000 \times \mathrm{g}$ ) in a microcentrifuge at $25^{\circ} \mathrm{C}$.

\section{Preparation of lichens for DNA extraction}

All non-disposable components used for washing or grinding were soaked in $1 \mathrm{M} \mathrm{HCl}$ to eliminate the possibility of DNA cross-contamination. Thalli were cleaned by hand, blade or tweezers under a dissecting microscope. Crustose lichens were scraped from the substratum with razor blades. Thalli with large amounts of surface contamination were washed by vortexing with glass beads and distilled water in a $15-\mathrm{ml}$ Falcon tube: about $10 \mathrm{ml}$ of beads were added to the tube followed by the fragmented lichen (c. $50-100 \mathrm{mg}$ ) and the tube completely filled with water. The lid was closed, and the inverted tube was vortexed as the lichen fragments rose to the top through the beads. The tube was inverted and vortexed again. Inversion and vortexing were repeated 5-10 times. The dirty water was then changed and the procedure repeated until the water remained clear after vortexing. The lichen was removed from the tube, blotted, air-dried, and weighed. Secondary products may also be removed, but it is not necessary to do so. Acetone was used to remove secondary products, and the thalli were air dried before weighing.

\section{DNA extraction protocol}

1. The clean, dry thalli are weighed. To keep liquid volumes within the capacity of one microfuge tube, not more than the following weights are used per extraction: $100 \mathrm{mg}$ dry weight at environmental moisture, or $50 \mathrm{mg}$ lyophilized dry weight. Too much material relative to the extraction buffer (see below) may produce poor results. While vortexing, shaking, or inverting the samples in microfuge tubes throughout the procedure, pressure should be kept on the lids to prevent accidental opening, as sand, heat, chloroform and detergents tend to weaken the tubes' seal.

2a. Routinely, tissue weighing more than $10-20 \mathrm{mg}$ is ground extensively in liquid $\mathrm{N}_{2}$ in a precooled mortar (c. five, 15-s grindings, interrupted by additions of liquid $\mathrm{N}_{2}$ ). The thoroughly ground powder is transferred into a 
$1 \cdot 5-\mathrm{ml}$ microfuge tube kept on ice (when many samples are processed in series, tubes with ground thalli are stored at $-80^{\circ} \mathrm{C}$ until all samples are ground). The tube is brought to room temperature and $5 \mathrm{tp} 10 \mathrm{vol}$. (w/v) of DTAB buffer supplemented with RNAase ( $1 \mu \mathrm{l}$ RNAase per $100 \mu 1$ DTAB) are added. The sample is thoroughly mixed with the extraction buffer by repeated inversion and shaking by hand before moving to step 3 .

2b. Amounts of air-dry tissue weighing less than 10-20 mg are best ground directly inside a microfuge tube at room temperature: approximately $50 \mu \mathrm{l}$ of very finely ground sand are added to the tube, followed by the thallus broken into small fragments. The dry tissue is then ground in the dry sand with a fitting pestle. During grinding the sand tends to pack on the bottom of the tube and needs to be periodically dislodged with the tip of the micropipette. When the tissue appears thoroughly fragmented, $100 \mu \mathrm{l}$ of DTAB-RNAase buffer is added, and grinding is continued for $2-5$ min more. Finally, the pestle is rinsed with an additional $100 \mu \mathrm{l}$ of DTAB-RNAase buffer added to the tube. Residual sand, which may cause leaks during the subsequent steps, is wiped off the rim and lid of the tube and the suspension is vortexed before proceeding to step 3 .

3. The extract is incubated at $70^{\circ} \mathrm{C}$ for $5 \mathrm{~min}$ to improve solubilization and nuclease inactivation. After mixing well by repeated inversion, the sample is pulsed in the microfuge for $1 \mathrm{~s}$ (the very short pulse removes material from the tube lid and rim without excessively packing the pellet). Chloroform is then added to equal the volume of DTAB buffer, the tube is closed tightly and the extract is mixed shaking by hand for 1-2 min. The pellet of sand and ground tissue must be completely resuspended. The sample is centrifuged for $2 \mathrm{~min}$ and the upper aqueous phase is transferred to a new tube $\left(^{\star}\right)$, avoiding contamination from the generally thick interface.

4. The transferred volume is measured with a pipette and 1.7-2 volumes of CTAB solution are added. The solutions are mixed by repeated inversion and centrifuged for $5 \mathrm{~min}$. After pouring off the supernatant immediately after the spin, the tube is not returned to an upright position and the excess liquid is removed from the internal walls of the inverted tube either by careful wiping with a wick of clean absorbent paper or through a Pasteur pipette hooked to a vacuum system. Caution must be exercised while suctioning, or the pellet may be lost. Residual liquid persisting on the very bottom around the pellet can be carefully removed with an automatic pipette.

5. The pellet is resuspended in $100 \mu 1 \mathrm{DTAB}$ (without RNAase) by repeated pipetting, keeping bubbles to a minimum. Some insoluble residue may remain in suspension (probably polysaccharide carry over or residues from the first $\mathrm{DTAB}$ /chloroform interface). Additional DTAB without RNAase is added to yield a final volume equal to one half of the DTAB volume used in step 2, and

(*) With some lichens the aqueous phase may be very viscous, due to excess polysaccharides. In such cases, after transfer of the aqueous phase to a new tube, an equal volume of fresh DTAB is added to the chloroform and to the interface of ground thallus left in the original tube, the components are well mixed, and phases are separated again by a 2 -min centrifugation. The upper aqueous phase is then pooled with the previous upper phase before proceeding to step 4 . 
the extract is heated at $70^{\circ} \mathrm{C}$ for $5 \mathrm{~min}$. Occasional traces of insoluble material can be pelleted with a $2-\mathrm{min}$ spin, and the supernatant is transferred to a new tube.

6. Chloroform is added to equal the volume of DTAB buffer, the tube is closed tightly and the extract is mixed shaking by hand for 1-2 min. The sample is centrifuged for $2 \mathrm{~min}$ and the upper phase is transferred to a new tube, avoiding contamination from the interface.

7. The volume is measured and the DNA is precipitated as indicated in step 4 , with special caution if suctioning through a vacuum system, as the pellet resulting from the second CTAB precipitation is very small or invisible.

8. The pellet is resuspended in $100 \mu \mathrm{l}$ of $1.2 \mathrm{M} \mathrm{NaCl}$ by repeated pipetting. If present, insoluble material may be pelleted again and the supernatant is transferred to a new tube. To re-precipitate the DNA, the sample is then mixed with $250 \mu \mathrm{l}$ of absolute ethanol at room temperature by repeated inversion.

9. The DNA precipitate is centrifuged for $5 \mathrm{~min}$. The supernatant is poured out and the excess is removed as in steps 4 and 7 . After addition of $1 \mathrm{ml}$ of $70 \%$ ethanol at room temperature without mixing, the sample is centrifuged again for $2 \mathrm{~min}$. The supernatant is removed as above, and residual ethanol is evaporated by leaving the open tube 5-10 min in a stream of air. It is best to leave the pellet moist with residual water, as genomic DNA is hard to resuspend after excessive dehydration. The sample is resuspended in $20-50 \mu \mathrm{l}$ of TE buffer or sterile water by repeated pipetting, and stored at $-20^{\circ} \mathrm{C}$.

10. When the expected amount of DNA is sufficiently high to be visualized by ethidium bromide staining, quantification is performed as follows: $1-10 \%$ of the sample, next to known amounts (5-50 ng) of intact or restricted lambda phage DNA (Promega), is subjected to agarose-gel electrophoresis ( $1 \%$ agarose) in the presence of ethidium bromide (Sambrook et al. 1989). The gel is photographed under UV light and the fluorescence of lichen DNA is compared to that of the standards.

We thank Chicita Culberson (Duke University) for hosting us in her laboratory during the initial phases of the project, François Lutzoni (Duke University) for suggesting the sand-grinding procedure, and Thomas Friedl (Universiry of Bayreuth) for testing the procedure on Trebouxia. The work was partially supported by grants from the North Carolina Biotechnology Center (ABIG882134) and the Swiss National Science Foundation (31-27817.89).

REFERENCES

Ahmadjian, V., Chadegani M., Koriem, A. M. \& Paracer, S. (1987) DNA and protoplast isolation from lichens and lichen symbionts. Lichen Physiology and Biochemistry 2: 1-11.

Armaleo, D. \& Clerc, P. (1991) Lichen chimeras: DNA analysis suggests that one fungus forms two morphotypes. Experimental Mycology 15: 1-10.

Blum, O. B. \& Kashevarov, G. P. (1986) DNA homologies as proof of legitimacy of the establishment of the lichen genus Lasallia Mérat (Umbilicariaceae). Doklady Akademii Nauk Ukrainskoi SSR Seriya B 1986 (12); 61-64 (in Russian). 
Common, R. S. (1991) The distribution and taxonomic significance of lichenan and isolichenan in the Parmeliaceae (Lichenized Ascomycotina), as determined by iodine reactions. I. Introduction and methods. II. The genus Alectoria and associated taxa. Mycotaxon 41: 67-112.

DePriest, P. T. \& Been, M. D. (1992) Numerous group I introns with variable distributions in the ribosomal DNA of a lichen fungus. fournal of Molecular Biology 228: 315-321.

Gargas, A. \& Taylor, J. W. (1992) Polymerase chain reaction (PCR) primers for amplifying and sequencing nuclear 18S rDNA from lichenized fungi. Mycologia 84: 589-592.

Gustincich, S., Manfioletti, G., Del Sal, G., Schneider, C. \& Carninci, P. (1991) A fast method for high-quality genomic DNA extraction from whole human blood. Bio Techniques 11: $298-301$.

Jones, A. S. (1963) Use of alkyltrimethylammonium bromides for the isolation of ribo- and the deoxyribo-nucleic acids. Nature 199: 280-282.

Kardish, N., Rotem-Abarbanell, D., Zilberstein, A. \& Galun, M. (1990) Comparison between the symbiotic Nostoc of the lichen Nephroma laevigatum Ach. and its cultured, isolated Nostoc by recombinant DNA. Symbiosis 8: 135-145.

Lutzoni, F. \& Vilgalys, R. (1995) Omphalina (Basidiomycota, Agaricales) as a model system for the study of coevolution in lichens. Cryptogamic Botany in press.

Murray, M. G. \& Thompson, W. F. (1980) Rapid isolation of high molecular weight plant DNA. Nucleic Acids Research 8: 4321-4325.

Sambrook, J., Fritsch, E. F. \& Maniatis, T. (1989) Molecular Cloning: A Laboratory Manual. 2nd Edn. Cold Spring Harbor, NY: Cold Spring Harbor Laboratory Press.

Taylor, J. W. \& Natvig, D. O. (1987) Isolation of fungal DNA. In Zoosporic Fungi in Teaching and Research (M. Fuller \& A. Jaworski, eds): 252-258 Athens, GA: Southeastern Publishing Corporation.

Zolan, M. E. \& Pukkila, P. J. (1986) Inheritance of DNA methylation in Coprinus cinereus. Molecular and Cellular Biology 6: 195-200. 
Downloaded from https:/www.cambridge.org/core. University of Basel Library, on 11 Jul 2017 at 09:07:34, subject to the Cambridge Core terms of use, available at https:/www.cambridge.org/core/terms. https://doi.org/10.1016/S0024-2829(95)80019-0 